\title{
Magnitude and factors associated with overweight and obesity among adolescents in semi-rural area of Babati District, Tanzania
}

FURAHINI D. TLUWAY'**, GERMANA H. LEYNA² and ELIA J. MMBAGA ${ }^{2}$

'Sickle Cell Disease Programme, 1 Kipalapala Road, Upanga, Dar es Salaam, Tanzania

${ }^{2}$ Department of Epidemiology \& Biostatistics, Muhimbili University of Health and Allied Sciences, School of Public

Health and Social Sciences, 9 United Nations Road, Dar es Salaam, Tanzania

\begin{abstract}
Background: Childhood and adolescent overweight and obesity have increased dramatically in recent years. We assessed the burden and factors associated with overweight and obesity among adolescents in a semi-rural district of Babati in Tanzania.

Methods: A school-based descriptive cross-sectional survey was conducted among adolescents attending secondary schools. Anthropometric measurements were taken using standard procedures. A Food Frequency Questionnaire and the International Physical Activity Questionnaire were adapted to assess dietary and physical activity patterns, respectively.

Results: A total of 619 students were included in the analysis. The mean age and body mass index of the respondents were $16.7 \pm 1.68$ years and $19.9 \pm 3.16 \mathrm{~kg} / \mathrm{m}^{2}$, respectively. The overall prevalence of overweight and obesity was $9.2 \%$ with more girls being overweight and obese than boys $(P<0.0001)$. In the Generalized Estimating Equations (GEE) models, girls (Odds Ratio [OR] = 5.6; 95\% Confidence Interval [Cl]: 1.97, 15.72]); unhealthy diet $(\mathrm{OR}=2.2 ; 95 \% \mathrm{Cl}: 1.32,3.63)$; vigorous physical activity $(\mathrm{OR}=2.2 ; 95 \% \mathrm{Cl}: 1.34,3.56)$ and physical inactivity (OR $=1.7 ; 95 \% \mathrm{Cl}: 1.08,2.79)$ were independent predictors of overweight or obesity.

Conclusion: The prevalence of overweight and obesity was modest. Female sex, unhealthy diet and physical inactivity were significantly predictive. There is a need for interventions in obesity to have a broader target audience to include adolescents and residents of rural areas. Primary preventive interventions are needed.
\end{abstract}

Keywords: adolescent, overweight, obesity, prevalence, factors, Tanzania

\section{Introduction}

Overweight and obesity are defined as abnormal or excessive fat accumulation that may impair health (WHO, 2013). There is strong evidence suggesting that overweight and obesity have reached epidemic proportions globally in all age groups (WHO, 2000). The recent Global Burden of Disease study, reported that the worldwide prevalence of overweight and obesity combined rose by $27 \cdot 5 \%$ and $47 \cdot 1 \%$ for adults and children respectively, between 1980 and 2013 ( $\mathrm{Ng}$ et al., 2013). A large proportion of the increase is believed to come from developing countries (WHO, 2013). Furthermore, the World Bank has projected an increase of 64\% in mortality (2008-2030) attributed to non-communicable diseases (NCDs) in Sub Saharan Africa, of which overweight or obesity are the major risk factors (Nikolic et al., 2011). Tanzania like many developing countries has not been spared from the effects of globalization and nutrition transition (Maletnlema, 2006). The country has experienced increased consumption of energy dense foods, high in fat, sugar and salt, as well as rising levels of sugary soft drinks sold in or near the school environment (Elliott, 2004). Some of these changes have even crossed the rural-urban divide in rural Tanzania although it is in its early stages (Mvo et al., 1999).

The prevalence of overweight or obesity among Tanzanian children and adolescents is estimated between $8.7 \%$ - 10.2\% with girls, private school children and those residing in urban areas being disproportionately affected (Frontini et al., 2003; Elliott,2004; Lobstein et al., 2004; Fungo \& Mosha, 2010; Gupta et al., 2012). Aside from the known risk factors, studies in children have shown that receiving pocket money affects the quality of foods consumed at school, decreases

${ }^{*}$ Correspondence E-mail: tluwayfd@gmail.com 
fruit/vegetable consumption, leads to skipping breakfast or intake of a poor nutritional value breakfast (Mwaikambo et al., 2015). Other factors such as use of motorized transport to and from school and increased sedentary recreation such as watching television and playing video games have also been associated with weight gain in children(Freedman et al., 2003; Peebles, 2008; Karl \& Supa, 2011; Baalwa et al., 2010;). However most of the literature on obesity from low- and middleincome countries comes from urban studies and among primary school children(Fungo \& Mosha, 2010; Mushengezi \& Chillo, 2014; Muhihi et al., 2013; Mpembeni et al., 2014; Mwaikambo et al., 2015). The variations observed in these studies, and the concentration of the studies in urban areas, has limited interpretation on the overall distribution of overweight or obesity in other age groups and across the country. This study was therefore carried out to estimate the prevalence and magnitude of modifiable risk factors among adolescents attending secondary schools in semi-rural settings of northern Tanzania.

\section{Materials and Methods}

\section{Study site and design}

This study was carried out in Babati district northern Tanzania $\left(460.86 \mathrm{~km}^{2}\right)$. The district has a total population of 93,108 and average the household size is 4.4 (Census 2012). This descriptive crosssectional school-based study involving both day and boarding schools was conducted in April 2014. The participants were adolescents attending private or public schools. This population was selected because majority of the students attending secondary schools in Tanzania fall within the World Health Organization (WHO) age range for adolescents (10-19 years).

Multi-stage cluster sampling was used to select schools, classes and students. The schools were stratified into private or public schools and sampled separately. Fifty percent (50\%) of all schools in each cluster were randomly sampled. Probability proportion-to-size was used to estimate the number of students to be recruited from each school. From each selected school, depending on class size, two streams or a whole class that approximated the required sample for that school was randomly selected. All students in the selected streams or class participated in the study. A self-administered questionnaire was used to collect data on socio-demographic characteristics, dietary habits, physical activity and sedentary behaviours. Participants were arranged mimicking an examination setting in the same room in the absence of their teachers.

\section{Assessment of dietary pattern, physical activity and anthropometric measures}

A short 15-item Food Frequency Questionnaire (FFQ) obtained from the guidelines for measuring household and individual dietary diversity (FAO, 2013), was used to assess dietary patterns of 6 food groups. These included potato chips, red meat, sweets and snacks, fizzy soft drinks, fruit and vegetables. Participants were asked to recall over the past week (7 days) the frequency of consumption of each food item. They were also asked if they took breakfast (type and frequency per week). Using a composite measure dietary habits were dichotomized as healthy or unhealthy. The International Physical Activity Questionnaire (IPAQ, 2002), was adapted, however workrelated physical activities questions were omitted. In the analysis the responses were grouped into a three-level ordinal variable (mild, moderate and vigorous physical activity).

Direct measures of weight $(\mathrm{kg})$ using a bathroom digital weighing scale (Omron, Japan) were taken. Height $(\mathrm{m}$ ) was measured using a Shorr height board (Weight and Measure, LLC, USA), using standard procedures (Cogill, 2003). All measurements were taken in duplicates with participants dressed minimally with no shoes. Measurements for boys and girls were done in different rooms to ensure privacy. Body mass index (BMI) was calculated as weight in kilograms divided by the square of height in meters $\left(\mathrm{kg} / \mathrm{m}^{2}\right)(\mathrm{WHO}, 2013)$ The International Obesity Task Force (IOTF) cut-offs for defining overweight and obesity in children between 2 and 18 years were used (Cole et al., 2007). 


\section{Data analysis}

Data processing was done using STATA version13.0 (Stata Corp LP, Texas, US). Descriptive statistics were used to summarize the data. Chi-square test was used to test statistical differences in proportion between categories of the explanatory variables. The relationship between select explanatory variables and probability of being overweight or obese for a given student from a given school was evaluated. Generalized Estimation Equation (GEE) models were fit using the STATA code. The best working correlation structure (in this case an exchange correlation structure) at the school level and the best covariate model was selected using the qic command. The classroom correlations were treated as nuanced. Analysis was two-tailed using a significance level of $5 \%$.

\section{Ethical considerations}

Ethical clearance to conduct the study was sought and obtained from the Muhimbili University of Health and Allied Sciences Research and Publication Ethical Committee. Permission was sought from the Regional and District administrative structures as well as from the school heads. Assent and written informed consents were sought from students and parents/guardians respectively before participation in the study.

\section{Results}

\section{Socio-demographic characteristics of the study population}

A total of 619 students from 8 ( 5 public and 3 private) secondary schools in Babati were included in the study. The mean age was $16.7 \pm 1.68$ years (range $=13-19$ years). A little over a half of the students (53.5\%) were between the age of 10 and 16 years. Over half (57.2\%) of the participants were females. The mean BMI of the participants was and $19.9 \pm 3.16 \mathrm{~kg} / \mathrm{m}^{2}$.About fifty-five percent of students (54.8\%) reported their father's and 38\% their mother's level of education as secondary education (Table 1 ).

Table 1: Socio-demographic characteristics of study population

\begin{tabular}{llll}
\hline Variable & Response & Number & Percentage \\
\hline Age (years) & $10-16$ & 331 & 53.5 \\
Sex & $17-20$ & 288 & 46.5 \\
Type of School & Male & 265 & 42.8 \\
& Female & 354 & 57.2 \\
Number of siblings & Private & 234 & 37.8 \\
& Public & 385 & 62.2 \\
Number of household members & $1-4$ & 524 & 84.7 \\
& More than 4 & 95 & 15.3 \\
Father's education & $1-4$ & 85 & 13.7 \\
& More than 4 & 534 & 86.3 \\
Mother's education & Primary or less & 280 & 45.2 \\
& Secondary+ & 339 & 54.8 \\
Father's occupation & Primary or less & 384 & 62.0 \\
& Secondary+ & 235 & 38.0 \\
& Employed & 179 & 29.4 \\
Mother's occupation & Farmer & 198 & 32.5 \\
& Business & 232 & 38.1 \\
History of smoking & Employed & 113 & 18.3 \\
\hline
\end{tabular}




\begin{tabular}{llll}
\hline \multirow{3}{*}{ Overweight or obese } & Yes & 4 & 0.6 \\
& No & 562 & 90.8 \\
& Yes & 57 & 9.2 \\
\hline
\end{tabular}

The overall prevalence of overweight or obese was 9.2\% (Table 2). Female sex $(P<0.0001)$, mother's education level $(P=0.017)$, father's occupation $(P=0.035)$, being given pocket money $(P=0.049)$ and eating unhealthy diet $(P=0.017)$ were significantly associated with overweight or obesity.

Table 2: Distribution of overweight or obesity status by select characteristics

\begin{tabular}{|c|c|c|c|c|c|}
\hline \multirow[b]{2}{*}{ Variable } & \multirow[b]{2}{*}{ Category } & \multicolumn{4}{|c|}{ Overweight or obese } \\
\hline & & $\mathrm{N}$ & No $(\%)$ & Yes (\%) & P value* \\
\hline \multirow[t]{2}{*}{ Age, years } & $10-16$ & 331 & 91.8 & 8.2 & \\
\hline & $17-20$ & 288 & 89.6 & 10.4 & 0.403 \\
\hline \multirow[t]{2}{*}{ Sex } & Male & 265 & 97.0 & 3.0 & \\
\hline & Female & 354 & 86.2 & 13.8 & $<0.0001$ \\
\hline \multirow[t]{2}{*}{ Type of School } & Private & 234 & $89 \cdot 3$ & 10.7 & \\
\hline & Public & 385 & 91.7 & 8.3 & 0.322 \\
\hline \multirow[t]{2}{*}{ Number of siblings } & $1-4$ & 524 & 90.3 & 9.7 & \\
\hline & More than 4 & 95 & 93.7 & 6.3 & 0.340 \\
\hline \multirow[t]{2}{*}{ Number of household members } & $1-4$ & 85 & 89.4 & 10.6 & \\
\hline & $>4$ & 534 & 91.0 & 9.0 & 0.685 \\
\hline \multirow[t]{2}{*}{ Father's education } & Primary or less & 280 & 92.9 & 7.1 & \\
\hline & Secondary+ & 339 & 89.1 & 10.9 & 0.106 \\
\hline \multirow[t]{2}{*}{ Mother's education } & Primary or less & 384 & 93.0 & 7.0 & \\
\hline & Secondary+ & 235 & 87.2 & 12.8 & 0.017 \\
\hline \multirow[t]{3}{*}{ Father's occupation } & Employed & 179 & 89.4 & 10.6 & \\
\hline & Farmer & 198 & 87.4 & 12.6 & \\
\hline & Business & 232 & 94.4 & 5.6 & 0.035 \\
\hline \multirow[t]{4}{*}{ Mothers occupation } & Employed & 113 & 88.5 & 11.5 & \\
\hline & Farmer & 168 & 89.9 & 10.1 & \\
\hline & Business & 181 & 92.3 & 7.7 & \\
\hline & Housewife & 155 & 91.6 & 8.4 & 0.689 \\
\hline \multirow[t]{3}{*}{ Physical activity level } & Mild & 203 & 91.6 & 8.4 & \\
\hline & Moderate & 331 & 90.9 & 9.1 & \\
\hline & Vigorous & 85 & 88.2 & 11.8 & 0.657 \\
\hline \multirow[t]{2}{*}{ Pocket money } & No & 294 & 93.2 & 6.8 & \\
\hline & Yes & 325 & 88.6 & 11.4 & 0.049 \\
\hline \multirow[t]{2}{*}{ Amount of money per term } & $<50000$ & 276 & 88.0 & 12.0 & \\
\hline & $>=50000$ & 49 & 91.8 & 8.2 & 0.626 \\
\hline \multirow[t]{2}{*}{ Unhealthy diet } & No & 452 & 92.5 & 7.5 & \\
\hline & Yes & 167 & 86.2 & 13.8 & 0.017 \\
\hline \multirow[t]{2}{*}{ Physical inactivity } & No & 270 & 89.6 & 10.4 & \\
\hline & Yes & 89 & 83.1 & 16.9 & 0.102 \\
\hline
\end{tabular}

* Chi square test except where expected cell value is $<5$ then Fisher's exact statistics is presented

In the adjusted multiple regression model (Table 3), girls had a five times increased odds of being overweight or obese than boys ( $\mathrm{aOR}=5.6 ; 95 \% \mathrm{Cl}: 1.97,15.72 ; \mathrm{P}<0.01)$. Unhealthy diet increased the odds of overweight or obesity by a factor of two (aOR=2.2; 95\% $\mathrm{Cl}: 1.32,3.63 ; \mathrm{P}<0.01$ ). Being categorized as participating in vigorous physical activity was associated with a two-fold increase in the likelihood of being overweight or obese ( $\mathrm{OR}=2.2 ; 95 \% \mathrm{Cl}: 1.34,3.56 ; \mathrm{P}<0.01)$. Adolescents who were sedentary had a $70 \%$ increased odds of being overweight or obese than their non-sedentary counterparts (OR=1.7; 95\% Cl: 1.08, 2.79). 
Table 3: Population average odds of overweight or obesity by demographic characteristics

\begin{tabular}{llll}
\hline Variable & Category & $(1)$ & $(2)$ \\
\hline Age, years & $10-16$ & 1.0 & 1.0 \\
Sex & $17-20$ & $1.3[0.74,2.38]$ & $1.3[0.72,2.53]$ \\
Father's education & Male & 1.0 & 1.0 \\
& Female & $5.2^{* *}[1.89,14.06]$ & $5.6^{* *}[1.97,15.72]$ \\
Mother's education & Primary or less & 1.0 & \\
& Secondary+ & $1.3[0.58,2.77]$ & 1.0 \\
Father's occupation & Primary or less & 1.0 & $1.5[0.64,3.69]$ \\
& Secondary+ & $1.4[0.70,2.97]$ & \\
Physical activity level & Employed & 1.0 & \\
& Farmer & $1.4[0.83,2.33]$ & 1.0 \\
Pocket money & Mild & $0.9[0.46,1.94]$ & $1.6[0.96,2.74]$ \\
& Moderate & 1.0 & $2.2^{* *}[1.34,3.56]$ \\
Unhealthy diet & Vigorous & $1.7^{*}[1.03,2.70]$ & \\
& No & $2.2^{* * *}[1.64,2.83]$ & 1.0 \\
Physical inactivity & Yes & 1.0 & $2.2^{* *}[1.32,3.63]$ \\
QIC & No & $1.1[0.37,3.00]$ & 1.0 \\
\hline Exponenta & Yes & 1.0 & $1.7^{*}[1.08,2.79]$ \\
& No & 1.0 & 241.265
\end{tabular}

Exponentiated coefficients: 95\% confidence intervals in brackets; Model (1) Crude Odds Ratio, Model (2) Adjusted for all variables in Table. ${ }^{*} p<0.05,{ }^{* *} p<0.01,{ }^{* * *} p<0.001$

\section{Discussion}

We observed a modest prevalence of overweight/obesity among adolescents in a semi-rural setting of Tanzania. Girls, unhealthy dietary habits, vigorous physical activity and sedentary behaviours were independently associated with overweight and obesity. The rising prevalence of childhood overweight and obesity is a serious public health concern given its established link to chronic diseases during childhood and adulthood (Rossouw et al., 2012). The observed prevalence is consistent with the prevalence of overweight and obesity reported among school children in urban areas of Tanzania (Mushengezi \& Chillo, 2014; Muhihi et al., 2013; Mpembeni et al., 2014; Mwaikambo et al., 2015). Similar findings have been reported in studies conducted in rural areas of South Africa and Tunisia (Rossouwet al., 2012; Aounallah-Skhiri et al., 2008). Our findings indicate that the prevalence of overweight/obesity is rising in rural areas and has now reached levels previously seen only in urban settings.

As in other studies we observed a differential sex prevalence of overweight/obesity, where girls had a higher prevalence than boys(Cogill, 2003; Lobsteinet al., 2004; Fungo \& Mosha 2010; Rossouw et al., 2012)It is possible that most of the girls in our study were at various stages of pubescent. Overweight or obesity in girls has been associated with the onset of menarche (Mukuddem-Petersen \& Kruger 2004; Kruger et al., 2006). There have been discussions of whether early onset of menarche contributes to overweight or obesity or if overweight or obesity causes early menarche (Elrick et al., 2002). We adjusted for age as a proxy for puberty in our final models. Other possible factors that can explain the sex difference include differences in energy needs between boys and girls (Kimani-Murage et al., 2010) and decline in physical activity in girls at earlier ages than boys.

Vigorous physical activity increased the odds of being overweight or obese similar to other studies (Gupta et al., 2012). This reverse in directionality is considered a compensatory behaviour, where students overestimate the amount of calories they have burned during exercising and treat themselves to more food or foods with more caloric value (Berli et al., 2014). This can be one explanation, but because the study did not directly observe the activity level of the participants it 
is also very likely that those who were obese/overweight over-reported their physical activity as a means to compensate. About 1 in 4 participants in this study were categorized as consuming unhealthy diets and this was associated with a higher prevalence of overweight or obesity. Unhealthy diet has been associated with obesity in other studies in East Africa in both rural and urban settings (Peebles, 2008; Fungo \& Mosha, 2010; Muhihi et al., 2013).

Alcohol consumption and tobacco use have been shown to contribute to overweight and obesity (Karl\& Supa2011; Baalwa et al., 2010).However, the prevalence of alcohol and cigarette/tobacco consumption reported in this study was very low, and may have been underreported due to fear of reprimand from school authorities. That said, other studies conducted in Tanzania, have shown on average alcohol consumption in adolescents is $30 \%$. This was more prevalent among males than females, and was associated with availability of alcohol and disposable income (Francis et al., 2015).Prevalence of cigarette smoking in Tanzania ranged has reported more in rural than in urban areas (Kitange et al., 1993).

Our study reported no association between school type, age, parent education and occupation status, and receiving pocket money with overweight or obesity as has been reported in other school-based studies in urban Tanzania, Kenya, Ghana and Brazil (Ricardo et al., 2009; Kyallo et al., 2013; Amidu et al., 2013; Mwaikambo et al., 2015).The homogeneity in socio-economic status amongst families who can afford secondary education for their children and non-differential bias in categorization of the participants with respect to the exposure status may partly explain the lack of an association.

The strengths of our study lie in it being conducted in a semi-rural setting among adolescents. We also used advanced modelling approaches to investigate the association between selected socio-demographic characteristics and behavioural factors and overweight and obesity. However, interpretation of our findings must be done with caution, due to some study limitations. The use of a cross-sectional study design precludes statements of cause-and-effect in observed associations. For example it is possible adolescents who were overweight or obese participated more in vigorous physical activity, as a response to try and attain preferred body images. Another limitation is that puberty and genetic factors that could have an effect on obesity were not assessed. However, age and sex were adjusted for in our regression models, where they were used as a proxy to capture the hormonal changes that occur during puberty in the different ages and sexes. We believe this may have minimized the confounding effect of fat deposition during puberty and hence realistic estimates given.

The reported dietary and physical activity tools were not validated for use in our setting. A pre-test was done to assess the face-validity of the tool with good response, an indication that the tool may have been valid in its assessment of self-reported habitual dietary intake and levels of physical activity. In addition, though questions were designed to be age appropriate and have a short recall period, we cannot rule out the possibility of recall bias.

In conclusion, this study has observed a modest prevalence of overweight and obesity amongst secondary school students in a semi-rural district of Tanzania. Female sex, unhealthy diet, vigorous physical activity and sedentary behaviours were independent predictors of overweight and obesity. There is a need for interventions in obesity and other non-communicable disease to have a broader target audience to include adolescents and residents of rural areas.

\section{Acknowledgements}

We would like to thank all the students, parents and guardians for consenting to participate in this study. We acknowledge the facilitation and cooperation from heads of schools and Local authorities, without which this study could not have been possible. We acknowledge the great work done by our research assistants namely Elias lyo and Pendo Daniel. 


\section{Conflicts of interest}

The authors declare that no competing financial interests exist.

\section{Author contributions}

FDT-design of the study, data collection, analysis and interpretation; draft of manuscript. GHL design of the study, analysis and interpretation, review of manuscript. EJM - analysis and interpretation, review of manuscript

\section{References}

Amidu, N., Owiredu, W., Saaka, M., Quaye, L., Wanman, M., Kumibea, P.D., Zingina, F.M.\& Mogre, V. (2013) Determinants of childhood obesity among basic school children aged $6-12$ years in Tamale Metropolis ( Ghana). Journal of Medical and Biomedical Sciences 2(3): 26-33.

Aounallah-Skhiri, H., Traissac, P., El Ati, J., Eymard-Duvernay, S., Landais, E., Anchour, N., Delpeuch, F., Romdhane, H. \& Maire, B. (2008). Nutritional status of Tunisian adolescents: associated gender, environmental and socio-economic factors. Public Health Nutrition Journal 11: 1306-1317.

Baalwa, J., Byarugaba, B., Kabagambe , E.\& Otim, A. (2010) Prevalence of overweight and obesity in young adults in Uganda. African Health Sciences 10(4): 367-373.

Berli, C., Loretini, P., Radtke, T., Hornung, R. \& Scholz, U. (2014) Predicting physical activity in adolescents: the role of compensatory health beliefs within the health action process approach. Psychology \& Health 29:458-474.

Cogill, B. (2003) Anthropometric Indicators Measurement Guide. Washington, DC. Food and Nutrition Technical Assistance (FANTA) Project, FHI 360.

Cole, T.J., Flegal, K.M., Nicholls, D. \& Jackson, A.A. (2007). Body mass index cut offs to define thinness in children and adolescents: international survey. BMJ335:194

Elrick, H.D., Samaras, T.T. \& Demas, A. (2002) Missing link in the obesity epidemic. Nutritional Research 22: 1101-1123.

FAO (2013) Guidelines for Measuring Household and Individual Dietary Diversity. Food and Agriculture Organization. Available at: www.fao.org/3/a-i1983e.pdf

Francis, J.M., Weiss, H.A., Mshana, G., Baisley, K., Grosskurth, H. \& Kapiga, S.H. (2015) The epidemiology of alcohol use and alcohol use disorders among young people in northern Tanzania. PLOS ONE 10:10.

Freedman, D.S., Khan, L.K., Serdula, M.K., Dietz, W.H., Srinivasan, S.R.\& Berenson, G.S.(2003) The relation of menarche age to obesity in childhood and adulthood: the Bogalusa heart study. BMC Pediatrics 3:3.

Frontini, M., Srinivasan, S.\& Berenson, G. (2003) Longitudinal changes in risk variables underlying metabolic syndrome $X$ from childhood to young adulthood in female subjects with a history of early menarche: the Bogalusa Heart Study. International Journal of Obesity Related Metabolic Disorders 27:1398-1404.

Fungo, S. \& Mosha, T. (2010) Prevalence of overweight and obesity among children aged 6-12 years in Dodoma and Kinondoni Municipalities, Tanzania. Tanzania Journal of Health Research 12: 6-16

Gupta, N., Goel, K., Shah, P. \& Misra, A. (2012) Childhood obesity in developing countries: epidemiology, determinants, and prevention. Endocrine Reviews33:48-57.

Karl, P. \& Supa, P. (2011) Overweight and obesity and associated factors among school-aged adolescents in Ghana and Uganda. International Journal of Environmental Research and Public Health 8: 3859-3870.

Elliott, K. (2004) Childhood obesity chronic care model. Arizona Health Care Cost Containment 
System.

Available

at:

http://www.improvingchroniccare.org/downloads/childhood_obesity_model_.pdf

IPAQ (2002) The International Physical Activity Questionnaire. Available at: youthrex.com/wpcontent/uploads/2017/06/IPAQ-TM.pdf.

Kimani-Murage, E.W., Kahn, K., Pettifor, J.M. Tollman, S.M., Dunger, D.B., Gómez-Olivé, S.F.\& Norris, S.A. (2010) The prevalence of stunting, overweight and obesity, and metabolic disease risk in rural South African children. BMC Public Health10:158.

Kitange, H.M., Swai, A.B., Masuki, G., Kilima, P.M., Alberti, K.G. \& McLarty, D.G. (1993) Coronary heart disease risk factors in sub-Saharan Africa: studies in Tanzanian adolescents. Journal of Epidemiology \& Community Health47:303-307.

Kruger, R., Kruger, H.S. \& MacIntyre, U.E. (2006) The determinants of overweight and obesity among 10- to 15-year-old schoolchildren in the North West Province, South Africa - the THUSA BANA (Transition and health during urbanisation of South Africans; BANA, children) study. Public Health Nutrition 9: 351-358.

Kyallo, F., Makokha, A. \& Mwangi, A.M. (2013) Overweight and obesity among public and private primary school children in Nairobi, Kenya. Health 5: 85-90.

Lobstein, T., Baur, L. \& Uauy, R. (2004) For the IASO International Obesity Task Force. Obesity in children and young people: a crisis in public health. The International Association for the Study of Obesity. Obesity Reviews 5 (Suppl. 1): 4-85.

Maletnlema, T.N. (2006) A Tanzanian perspective on the nutrition transition and its implications for health. Public Health Nutrition 5(1A): 163-168.

Mpembeni, R., Muhihi, A.J., Maghembe, M., Ngarashi, D., Lujani, B., Chillo, O., Kubhoja, S., Anael, A. \& Njelekela, M.A. (2014) Overweight, obesity and perceptions about body weight among primary schoolchildren in Dar es Salaam, Tanzania. Tanzania Journal of Health Research 16: 185-192.

Muhihi, A.J., Mpembeni, R., Njelekela, M.A., Anaeli, A., Chillo, O., Kubhoja, S., Lujani, B., Maghembe, M.\& Ngarashi, D.(2013) Prevalence and determinants of obesity among primary school children in Dar es Salaam, Tanzania. Archives of Public Health 71:26.

Mukuddem-Petersen, J. \& Kruger, H.S. (2004) Association between stunting and overweight among 10-15-year-old children in the North West Province of South Africa: The THUSA BANA Study. International Journal of Obesity 28:842-851.

Mushengezi, B. \& Chillo, P. (2014) Association between body fat composition and blood pressure level among secondary school adolescents in Dar es Salaam, Tanzania. Pan African Medical Journal 19:327.

Mvo, Z., Dick, J. \& Steyn, K. (1999) Perceptions of overweight African women about acceptable body size of women and children. Curationis 22:27-31.

Mwaikambo, S.A., Leyna, G.H., Killewo. J., Simba, A. \& Puoane, T. (2015) Why are primary school children overweight and obese? A cross sectional study undertaken in Kinondoni district, Dar-es-Salaam. BMC Public Health 15:1269.

Ng, M., Fleming, T., Robinson, M., Thomson, B., Graetz, N., Margono, C., Mullany, E.C., Biryukov, S., Abbafati, C., Abera, S.F., Abraham, J.P., Abu-Rmeileh, N.M., Achoki, T.et al. (2014). Global, regional, and national prevalence of overweight and obesity in children and adults during 1980-2013: A systematic analysis for the Global Burden of Disease. Lancet 384(9945): 766 781. 
Nikolic, I.A., Stanciole, A.E., \& Zaydman, M. (2011) Chronic Emergency: Why NCDs Matter. Health, Nutrition and Population (HNP) discussion paper. World Bank, Washington, DC. [http://www.worldbank.org/en/search?q=ncds+projection\&current]

Peebles, R. (2008) Adolescent obesity: aetiology, office evaluation, and treatment. Adolescent Medicine: State of the Art Reviews 19:380-405.

Ricardo, G., Caldeira, G. \& Corso, A. (2009). Prevalence of overweight and obesity and adiposity central indexes among school-aged children in Santa Catarina, Brazil. Revista Brasileira de Epidemiologia 12(3):1-12.

Rossouw, H., Grant, C. \& Viljoen, M. (2012). Overweight and obesity in children and adolescents: The South African problem. South African Journal of Sciences 108(5/6): Art. \#907. 